\title{
Maps, Figures, and Tables
}

MAPS

I. The Pearl River delta 14

2. Shawan and surroundings $\quad$ I6

3. Cheung Chau 106

4. The Mirs Bay area $\quad$ I24

5. The Sha Tau Kok reclamation, I825 $\quad$ I28

6. Sha Tau Kok (Tung Wo) Market, I853 I38

7. The Shap Yeuk (Alliance of Ten) 150

8. Sketch map of the Tangang-Shuibian border $\quad$ I70

FIGURES

I. Sha Tau Kok from the west $\quad$ I30

2. The Sha Tau Kok reclamation 133

3. Shops in Sha Tau Kok (section) $\mathrm{I}_{42}$

4. Shops in Sha Tau Kok (floor plan) $\quad$ I44

TABLES

I. Landholding on the Sha Tau Kok reclamations by villages I3I

2. Budgeted incomes and expenditures, I920-I93I 